\title{
Quality of life in skin diseases as perceived by patients and nurses
}

\author{
Beata Kowalewska ${ }^{1}$, Barbara Jankowiak ${ }^{1}$, Elżbieta Krajewska-Kułak ${ }^{1}$, Dzmitry Fiodaravich Khvorik ${ }^{2}$, \\ Wiaczesław Niczyporuk ${ }^{3}$
}

${ }^{1}$ Department of Integrated Medical Care, Medical University in Bialystok, Bialystok, Poland

${ }^{2}$ Department of Dermatovenereology, Medical University of Grodno, Grodno, Belarus

${ }^{3}$ Faculty of Health Sciences, Lomza State University of Applied Sciences, Lomza, Poland

Adv Dermatol Allergol 2020; XXXVII (6): 956-961

DOI: https://doi.org/10.5114/ada.2019.86182

\begin{abstract}
Introduction: The appearance of the skin and its appendages not only reflects the general body condition, but also exerts an effect on one's self-esteem and self-image, and the way he/she is perceived by the others.

Aim: To analyse the quality of life (QOL) in dermatological diseases, assessed by the patients themselves and the nurses being their caregivers.

Material and methods: The survey was completed by 300 patients diagnosed with various dermatological conditions; however, only the data from 281 surveys were considered during the analysis. All patients completed an anonymous questionnaire designed specifically for the purpose of the study. The survey included 32 questions. Moreover, the study patients were surveyed with the Dermatology Life Quality Index (DLQI). Moreover, the study included 1713 nurses employed in various healthcare institutions and providing care to patients with dermatological diseases. The survey for the nurses consisted of 32 questions.

Results: Mean DLQI score for the study patients was $12.4 \pm 8.1$ points. Based on the median, lower and upper quartile values, every fourth person presented with DLQI scores $>18$ points, half of the respondents had DLQI scores no greater than 12 points, and every fourth respondent experienced good QOL (DLQI score no higher than 5 points). Conclusions: According to the majority of patients and nurses, individuals with skin conditions are not fully able to cope with their disease and show a negative attitude towards it. The QOL of patients with skin diseases is determined by the type of the dermatological condition.
\end{abstract}

Key words: quality of life, patients, nurses, dermatoses, Dermatology Life Quality Index.

\section{Introduction}

Beginning in the 1970s, a holistic approach, which has also become popular in medicine, stimulated interest in the quality of life $(\mathrm{QOL})$ of both healthy persons and patients suffering from various ailments. According to Siegrist and Jung [1], QOL comprises three interconnected elements of human life: physical indicators (pain and disability), psychological preconditions (mood, the level of anxiety and depression) and social preconditions (the degree of social isolation and the ability to play social roles) [1]. Skin, the vital organ of the human body, has a plethora of functions, acting as a protective barrier, being involved in communication with the environment, playing an aesthetic, perceptive, expressive and sexual role, to mention a few. Skin is an essential medium to both express and perceive emotions, and as such, plays a pivotal role during interpersonal contacts. The appearance of the skin and its appendages not only reflects the general body condition, but also exerts an effect on one's self-esteem and self-image, and the way he/she is perceived by the others [2-4]. Hence, individuals suffering from various dermatological conditions have usually distorted self-image and tend to estimate their $\mathrm{QOL}$ as low [5-8]. Patients with dermatological diseases consider themselves disfigured, stigmatized or even repulsive, especially if pathological lesions cover a large area of the skin, including genitals and visible parts, such as the face and hands. These emotions may negatively affect the psychological condition of dermatological patients, exert unfavourable effect on their families, social and

Address for correspondence: Beata Kowalewska MD, PhD, Department of Integrated Medical Care, Medical University of Bialystok, 7 A Marii Sklodowskiej-Curie, 15-096 Białystok, Poland, phone: +48 8574855 28,

e-mail: mocnakawa1@gmail.com, beata.kowalewska@umb.edu.pl

Received: 11.04.2019, accepted: 24.05.2019. 
professional functioning, and are the key determinants of worsened QOL $[3,9,10]$.

\section{Aim}

The aim of the study was to analyse the QOL in dermatological diseases, assessed by the patients themselves and the nurses being their caregivers.

\section{Material and methods}

The survey was completed by 300 patients diagnosed with various dermatological conditions; however, only the data from 281 surveys were considered during the analysis. The majority of the study group were women (59.8\%). The age of the study participants ranged between 20 and more than 60 years. The study patients most often presented with psoriasis (40.9\%), allergic diseases (19.5\%) and angiopathy (9.2\%). Other less frequently diagnosed conditions included connective tissue diseases (7.5\%), sebaceous and sweat gland disorders (4.3\%), erythematous dermatitis (3.5\%), fungal infections (2.8\%), parasitic infestations (2.5\%), bullous diseases (2.1\%), bacterial infections (1.8\%), hair diseases and sexually transmitted diseases (1.1\% each), viral infections, skin cancers ( $0.7 \%$ each) and other disorders (0.4\%); in some cases, an ultimate diagnosis has not been established at the time of the survey. The pathological lesions involved lower (37.4\%) and upper extremities (31.3\%), the whole body (29.9\%), trunk (20.3\%) and head/face (19.6\%). Sporadically, the skin disease was limited to the area around the joints (4.6\%).

Moreover, the study included 1713 nurses employed in various healthcare institutions and providing care to patients with dermatological diseases. The age of the study nurses ranged between 20 and 60 years.

The nurses typically provided care to patients with psoriasis (46.1\%), fungal infections (33.1\%), allergic diseases (28.3\%), crural ulcerations (14.8\%), scabies (14.5\%) and pressure ulcers (13.7\%). Other less often treated conditions included atopic dermatitis (10.4\%), inflammatory rash $(9.2 \%)$, urticaria (6.5\%), eczema $(5.7 \%)$, herpes zoster (5.4\%), erysipelas (3.5\%) and juvenile acne (2.8\%).

The patients supervised by the study nurses most often presented with skin lesions on the extremities (39.0\%), the trunk (28.3\%), whole body (21.4\%), feet (17.2\%), hands (16.8\%), face (16.8\%), buttocks (10.7\%) and head (10.5\%). The less frequent locations of dermatological lesions included groins (7.9\%), cubital and popliteal fossa (4.6\%), coccyx (4.0\%), female external genitals $(0.2 \%)$ and mucosal membranes (0.1\%); $3.5 \%$ of the study nurses did not specify the location of skin lesions in their patients.

All patients completed an anonymous questionnaire designed specifically for the purpose of the study. The survey included 32 questions, among others about pa- tient's age, sex, education, the source of income, living conditions, dermatological diagnosis, location of pathological lesions, attitude to the disease, and utilization of healthcare services. Moreover, the study patients were surveyed with the Dermatology Life Quality Index (DLQI), a standardized scale to measure the influence of skin lesions on QOL, developed by Finay and Khan [11], in Polish adaptation by Szepietowski et al. [12]. DLQI is designated to be used in both the inpatient and outpatient setting and measures the impact of the skin disease on the respondent's life over the previous week. The survey centres around the QOL in the following domains: symptoms and feelings related to the disease, activities of daily living (ADLS), leisure time, work or study, interpersonal relationships and treatment. Particular emphasis is put on the assessment of disability and impaired functioning due to the dermatological disease, whereas emotional effects of the condition are addressed by only one out of ten statements included in the DLQI [11, 12].

DLQI consists of ten statements, each scored on a four-item scale (0 - no impact, 1 - small impact, 2 large impact, and 3-maximum impact on the patient's $\mathrm{QOL})$. The global DLQI score may range between 0 and 30 points and is interpreted as follows:

- 0-1 point - no effect on the patient's QOL,

$-2-5$ points - small effect on the patient's QOL,

- 6-10 points - moderate effect on the patient's QOL,

- 11-20 points - very large effect on the patient's QOL

-21-30 points - extremely large effect on the patient's QOL [11, 12].

After summing up the scores for individual statements and calculating the global scores, mean DLQI values were stratified according to the type of the dermatological condition. Based on the results, the skin diseases were classified into two groups, with a large (high DLQI scores: 11-30 points) and small impact on the patient's QOL (low DLQI scores: 0-10 points).

The survey for the nurses consisted of 32 questions referring, among others, to the frequency of professional contacts with dermatological patients, localization of pathological lesions and opinions about patients' attitudes towards their disease.

\section{Ethics}

The study protocol was approved by the Local Bioethical Committee at the Medical University of Bialystok.

\section{Statistical analysis}

The results were summarized as frequencies for nominal variables and descriptive statistics for quantitative variables (such as DLQI scores). The $\chi^{2}$ test and Fisher's exact test were used to verify whether the relationships present in the sample were random or reflected a tendency occurring in the general population. 
Moreover, analysis of variance (ANOVA) was conducted to compare mean DLQI scores for patients suffering from various dermatological conditions; only the diseases found in at least 5 patients were considered during the analysis.

\section{Results}

The study patients presented with eleven different attitudes towards their disease, whereas nurses with seven (Table 1). The majority of the study patients (48.7\%) had a positive attitude towards their disease, expressed by the statement 'I believe that everything will be all right'. Also, in the opinion of $30.8 \%$ of the study nurses, dermatological patients showed a positive attitude towards their disease. The statement 'I have an impression that everything has turned against me' was chosen by $14.9 \%$ and $22.0 \%$ of the patients and nurses, respectively, the statement ' $\mathrm{t}$ is impossible that I have become ill' by $13.5 \%$ and $21.9 \%$, respectively, and the statement 'Someone had to develop the disease' by $11.4 \%$ and $14.7 \%$, respectively (Table 1).

Interestingly, the majority of the patients who declared a positive attitude towards their disease chose the answer 'not completely' when asked if they were able to cope with their dermatological conditions. A similar opinion was also shared by $15.8 \%$ of the nurses. An indifferent attitude to the disease was declared by $21 \%$ of the patients but no nurse. The statement 'The illness does not interfere with my life' was chosen by $18.7 \%$ of the patients, but only $3.2 \%$ of the nurses, whereas the statement 'I will never be able to fully cope with my illness' by $18.9 \%$ of the patients and no nurse. In nurses' opinion, the degree to which the patients were able to cope with their disease depended on the type (50.7\%) and location of the latter (21.1\%). Only a few patients (0.4\%) declared that they need to struggle with their illness (Table 2).

Asked about their general feelings related to the disease, most patients presented negative attitudes,

Table 2. The opinion of patients and nurses on the patient's coming to terms with their skin disease

\begin{tabular}{lccc}
\hline $\begin{array}{l}\text { Have you come to terms with } \\
\text { your disease }\end{array}$ & $\begin{array}{c}\text { Patient } \\
(n=281)\end{array}$ & $\begin{array}{c}\text { Nurses } \\
(n=1713)\end{array}$ & $P$-value \\
\hline Not entirely & $40.1 \%$ & $15.8 \%$ & NS \\
\hline I don't care & $21.0 \%$ & - & NS \\
\hline I'll never accept my illness & $18.9 \%$ & - & NS \\
\hline $\begin{array}{l}\text { Yes, it does not interfere } \\
\text { with my life }\end{array}$ & $18.9 \%$ & $3.2 \%$ & NS \\
\hline I must fight it & $0.4 \%$ & - & NS \\
\hline $\begin{array}{l}\text { It depends on the kind of illness } \\
\text { It depends on the localization } \\
\text { of lesions }\end{array}$ & - & $50.7 \%$ & NS \\
\hline \begin{tabular}{l} 
It's hard to say \\
\hline
\end{tabular} & $0.7 \%$ & $9.1 \%$ & NS \\
\hline
\end{tabular}

Table 1. The opinion of patients and nurses on the patient's attitude to skin disease

\begin{tabular}{lccc}
\hline Attitude to disease & $\begin{array}{c}\text { Patient } \\
(n=281)\end{array}$ & $\begin{array}{c}\text { Nurses } \\
(n=1713)\end{array}$ & $P$-value \\
\hline $\begin{array}{l}\text { Everything is going to be } \\
\text { all right }\end{array}$ & $48.7 \%$ & $30.8 \%$ & 0.005 \\
\hline $\begin{array}{l}\text { Everything has turned } \\
\text { against me }\end{array}$ & $14.9 \%$ & $22.0 \%$ & 0.03 \\
\hline I can't have fallen ill & $13.5 \%$ & $21.9 \%$ & 0.03 \\
\hline Someone has to fall ill & $11.4 \%$ & $14.7 \%$ & $\mathrm{NS}$ \\
\hline I don't care & $4.6 \%$ & $14.5 \%$ & $<0.001$ \\
\hline $\begin{array}{l}\text { Nobody is to blame for my } \\
\text { disease }\end{array}$ & $1.8 \%$ & - & $\mathrm{NS}$ \\
\hline Disease disturbs my life & $1.1 \%$ & - & $\mathrm{NS}$ \\
\hline It's the parents' guilt & $0.7 \%$ & $1.9 \%$ & $<0.001$ \\
\hline It's because of stress & $0.4 \%$ & - & $\mathrm{NS}$ \\
\hline It's the doctor's guilt & $0.4 \%$ & - & $\mathrm{NS}$ \\
\hline $\begin{array}{l}\text { All depends on aggravation } \\
\text { of lesions }\end{array}$ & $0.4 \%$ & - & $\mathrm{NS}$ \\
\hline $\begin{array}{l}\text { I'm ashamed of my disease } \\
\text { It's hard to say }\end{array}$ & - & $0.8 \%$ & $\mathrm{NS}$ \\
\hline
\end{tabular}

choosing the statements 'I feel anxious' (37.3\%), 'Everything irritates me' (17.8\%), 'I feel tired' (16.4\%) and 'I feel embarrassed' (1.1\%). Similar opinions were also presented by the study nurses who believed that their dermatological patients experience anxiety (48.1\%), irritability (22.4\%), fatigue (10.5\%) and embarrassment (2.1\%) (Table 3).

The distribution of DLQI scores in the study patients was as follows: $0-5$ points $-19 \%, 6-10$ points $-21 \%$, $11-15$ points $-22 \%, 16-20$ points $-15 \%$, 21-25 points $-13 \%$, and 26 and more points - 9\%. As shown above, the study group included both patients with the lowest DLQI scores and individuals with the highest pos-

Table 3. The opinion of patients and nurses on the patient's overall feeling connected with the disease

\begin{tabular}{lccc}
\hline $\begin{array}{l}\text { Have you come to terms with } \\
\text { your disease? }\end{array}$ & $\begin{array}{c}\text { Patients } \\
(n=281)\end{array}$ & $\begin{array}{c}\text { Nurses } \\
(n=1713)\end{array}$ & $P$-value \\
\hline I feel anxious & $37.3 \%$ & $48.1 \%$ & 0.04 \\
\hline I feel normal & $23.5 \%$ & $13.0 \%$ & $<0.001$ \\
\hline Things irritate me & $17.8 \%$ & $22.4 \%$ & NS \\
\hline I'm tired & $16.4 \%$ & $10.5 \%$ & 0.01 \\
\hline I feel restrained & $1.1 \%$ & $2.1 \%$ & NS \\
\hline I'm relaxed & $2.1 \%$ & $0.1 \%$ & NS \\
\hline It improves with my treatment & $1.4 \%$ & & NS \\
\hline $\begin{array}{l}\text { There are more serious worries } \\
\text { than skin disease }\end{array}$ & - & $0.1 \%$ & NS \\
\hline It's hard to say & $0.4 \%$ & $3.3 \%$ & NS \\
\hline
\end{tabular}


sible scores. Mean DLQI score for the study patients was $12.4 \pm 8.1$ points. Based on the median, lower and upper quartile values, every fourth person presented with DLQI scores > 18 points, half of the respondents had DLQI scores no greater than 12 points, and every fourth respondent experienced good QOL (DLQI score no higher than 5 points).

The highest mean DLQI scores were found in patients with fungal infections (19.3\%), parasitic infestations (17.2\%), skin necrosis (15.0\%) and viral infections (14.5\%). The QOL of patients with three most common dermatological diseases (psoriasis, allergies and angiopathies) was essentially the same, with mean DLQI scores of 13.5 points. Regarding other dermatological conditions, mean DLQI scores for erythematous dermatitis, erythematous-squamous and papular dermatitis amounted to 12.0 points, for pigment alterations to 10.0 points, for hair diseases to 9.7 points, for sexually transmitted diseases to 9.5 points, and for sebaceous and sweat gland disorders to 8.7 points. The lowest mean DLQI scores were observed in the case of connective tissue disorders (6.1 points), bacterial infections (6.0 points), bullous diseases (5.7 points) and neoplastic diseases of the skin/ skin cancer (3.0 points). Based on the result of ANOVA ( $p<0.0001)$, QOL in dermatological patients depended on the type of their illness.

According to $75.8 \%$ of the study patients, the attitude of healthcare personnel to persons with dermatological diseases is the same as to individuals with other conditions. This opinion was also shared by the majority of the study nurses who declared that both physicians (50.3\%) and nursing staff (66.7\%) treat dermatological patients identically as other persons. However, $12.1 \%$ of the study patients stated that they were treated by healthcare personnel "differently" and another $12 \%$ were unable to define the healthcare personnel's attitude. The vast majority of the patients who considered themselves treated worse claimed that they experienced inferior treatment from nurses, rather than from physicians. According to the study nurses, depending on the type of treatment, some physicians and nursing personnel providing care to patients with skin diseases ( $24.5 \%$ and $22.8 \%$, respectively) might be afraid of being infected (11.0\% and $6.8 \%$, respectively), feel repulsion ( $4.3 \%$ and $1.4 \%$, respectively) or show an indifferent attitude $(6.9 \%$ and $1.5 \%$, respectively).

\section{Discussion}

The appearance of the skin and its appendages is considered not only a source of information about the general body condition but also an important determinant of one's self-esteem and the way this person is perceived by the others. Hence, patients with dermatological diseases typically present with a distorted self-image and worsened QOL [13]. They consider themselves disfigured, stigmatized or even repulsive, especially if pathological lesions cover a considerable area of the skin, particularly external genitals and exposed areas, such as face and palms. These emotions exert an adverse effect on the psychological condition of dermatological patients, negatively affect their families, social and professional lives, and contribute to a dramatic decrease in their QOL [13].

According to Magin et al. [14], acne hinders the social functioning of patients and constitutes a major psychological problem, contributing to lower self-esteem and being a source of anxiety and depression. Moreover, dermatological diseases were shown to exert an unfavourable effect on social functioning. Dooley and Finlay [15] demonstrated that $17 \%$ of psoriasis patients felt embarrassed when others noticed their skin lesions or asked questions about their disease. According to Ginsburg et al. [16], dermatological patients feel stigmatized; specifically, they are sensitive to others' opinions, anticipate being rejected, have low self-esteem, experience the sense of damage, guilt and shame, and have an urge to keep their disease a secret.

While up to $48.7 \%$ of patients participating in our present study declared a positive attitude to their dermatological condition, $40.1 \%$ of them chose the response 'not completely' when asked about their ability to cope with the disease. Assessing their general condition, the study patients tended to choose negative responses, such as 'I feel anxious' (37.3\%) and 'Everything irritates me' (17.8\%). In turn, in the study nurses' opinion, dermatological patients have a generally positive attitude to their illness and believe that their condition is to be improved (30.8\%). However, a large proportion of the nurses stated that their patients were unable to adequately cope with their dermatological condition (58.8\%), and approximately half of the nursing staff (50.7\%) believed that the self-attitude toward dermatological disease is condition-specific.

Stankler [17] showed that more than $80 \%$ of psoriatics, both men and women, considered the embarrassment associated with the presence of pathological lesions on exposed parts of their bodies as the worst feature of their disease. This observation is consistent with the results of the study conducted by Devrimci-Ozguven et al. [18] who demonstrated that psoriasis patients had a significantly higher degree of depression than healthy controls. Similar findings were also reported by Gupta et al. [19] who analysed the prevalence of depression and suicidal thoughts among psoriatics. The study demonstrated that a group of 480 patients with skin diseases, such as acne, alopecia areata, atopic dermatitis and psoriasis, contained a significant proportion of individuals with depression. Moreover, $9.7 \%$ of the patients declared that they had suicidal thoughts [19].

According to Roenick et al. [20], psoriasis patients considered their bodies impure and complained that some people believed that their disease was contagious. According to the authors of that study, in the case of 
psoriasis patients, elements of stigmatization seem to be particularly important, such as the sense of having a scar, higher sensitivity to others' opinions, anticipation of being rejected, feelings of guilt and shame, secrecy, and paradoxical positive attitude being in fact a manifestation of desperation [20]. Dermatological patients often describe their skin diseases as more bothersome than some other somatic conditions. According to Żelazny et al. [9], in patients' opinion, skin diseases are much worse than assessed by their physicians. This is with no doubt associated with the presence of skin lesions on exposed body parts and resultant distortion of self-image, social rejection and the sense of being stigmatized.

In the present study, $18.9 \%$ of the patients declared that the disease interfered with their normal life. Furthermore, $0.4 \%$ of the respondents stated that they need to fight their illness, as it not only contributes to their selfdiscrimination, but even more importantly, makes them stigmatized and stimulates negative feelings (reluctance, disgust, aversion) in the others.

In the study conducted by Reich et al. [21], 49\% of psoriasis patients declared that the disease had a huge negative impact on their life overall, and $40 \%$ stated that the condition contributed to a substantial deterioration of their self-esteem. Nevertheless, a considerable proportion of the patients believed that their disease could be treated in the future.

The scales used to objectively assess the impact of a dermatological disorder on the QOL can be divided into three groups: 1) universal questionnaires, evaluating one's QOL based on health status determined with a generic scale, e.g. Nottingham Health Profile (NHP), Patient Generated Index (PGI), 2) dermatology-specific questionnaires, examining QOL of patients with any chronic disease of the skin, e.g. Dermatology Life Quality Index (DLQI), Skindex, VQ Dermato, and 3) disease-specific questionnaires dedicated to patients with some specific dermatological conditions, such as acne or psoriasis [22]

In this study, we used DLQI, a questionnaire designed by Finley and Khan for the assessment of patient's health status over the previous week in both inpatient and outpatient settings [11]. DLQI is used to evaluate QOL in the following domains: symptoms and illness-related feelings, ADLs, leisure activities, work or study, interpersonal relationships and treatment. The questionnaire focuses on disability and functional impairment resulting from the skin disease, rather than on emotional aspects of the latter which are addressed by only 1 out of 10 statements included in the DLQI [11].

Our study demonstrated that QOL of dermatological patients depended on the type of skin disease they suffered. Mean DLQI score for the whole study group was $12.4 \pm 8.1$ points. Patients with three the most common skin disorders present in our series (psoriasis, allergies and angiopathies) had essentially the same DLQI scores (13.5 points). Some dermatological conditions, namely connective tissue disorders, sebaceous and sweat gland diseases and bullous diseases, were associated with slightly higher mean DLQI scores, whereas others, such as fungal infections and parasitic infestations, were characterized by lower mean DLQI values.

takuta et al. [23] found a relationship between the anatomical location of psoriatic lesions and the sense of being stigmatized, negative emotional attitude towards the body, depression and social anxiety.

The quality of care offered by nurses is vital for the overall assessment of healthcare services provided by a given institution [24]. Hence, nurses should be aware that their attitudes and behaviours create the first impression, influencing greatly subjective feelings of patients during future hospitalizations $[25,26]$.

The vast majority of patients participating in our present study (84\%) believed that the management of a dermatological patient does not constitute an extra burden for the nurse; yet, a substantial proportion of the study participants (35.3\%) declared that nurses treated them worse than persons with healthy skin, which was primarily associated with a fear of contamination (20.7\%). In contrast, the surveyed nurses stated that both non-dermatology physicians (50.3\%) and non-dermatology nurses (66.7\%) treat patients with skin problems no worse than persons with other conditions.

To summarize, using a holistic and interdisciplinary approach to patients with dermatological conditions, we can identify, sometimes occult, a link between various psychological disorders and diseases of the skin. The latter may be triggered or exacerbated by many factors, such as genetic predisposition, immunological status, some medications, personality traits, stress, personal resources, low self-esteem or injuries [27]. A disease of the skin and/or its appendages triggers a psychological response (fear, shame, anger, depression), impairs social functioning (work, family life, leisure and social activities, sexual activity) and causes objective inconveniences (e.g. need for long-term pharmacotherapy, frequent visits to healthcare institutions, lifestyle modifications), which has eventually a detrimental effect on patient's QOL.

\section{Conclusions}

According to the majority of patients and nurses, individuals with skin conditions are not fully able to cope with their disease and show a negative attitude towards it. QOL of patients with skin diseases is determined by the type of the dermatological condition. Most patients and nurses declared that the attitude of healthcare personnel to patients with dermatological conditions is the same as in the case of individuals with other diseases.

\section{Conflict of interest}

The authors declare no conflict of interest. 


\section{References}

1. Siegrist J, Jung A. Conceptual and methodological problems in quality of life in clinical medicine. Soc Sci Med 1989; 29: 463-70.

2. Stein DJ, Hollander E. Dermatology and conditions related to obsessive-compulsive disorder. J Am Acad Dermatology 1992; 26: 237-42.

3. Zarek A. Factors influencing body image in individuals with selected dermatological diseases. Ann Acad Med Stetin 2014; 60: 75-87.

4. Jankowiak B, Kowalewska B, Khvorik FD, et al. The level of stigmatization and depression of patients with psoriasis. Iran J Public Health 2016; 45: 690-2.

5. Gupta MA, Gupta AK. Psychiatric and psychological comorbidity in patients with dermatologic disorders: epidemiology and management. Am J Clin Dermatol 2003; 4: 833-42.

6. Rapp DA, Brenes GA, Felman SR, et al. Anger and acne: implications for quality of life, patient satisfaction and clinical care. Br J Dermatol 2004; 151: 183-9.

7. Zacharie R, Zacharie C, Ibsen H, et al. Dermatology life quality idem: data Danish inpatients and outpatients. Acta Derm Venerol 2003; Suppl. 2: 78-86.

8. Kowalewska B, Krajewska-Kułak E, Wrońska I, et al. Selfassessment of quality of life in patients with dermatological disorders. Dermatol Klin 2010; 12: 106-13.

9. Żelazny I, Nowicki R, Majkowicz M, Samet A. Jakość życia w chorobach skóry. Przew Lek 2004; 9: 60-5.

10. Jankowiak B, Sekmistrz S, Kowalewska B, et al. Satisfaction with life in a group of psoriasis patients. Adv Dermatol Allergol 2013; 30: 85-90.

11. Finlay AY, Khan GK. Dermatology Life Quality Index (DLQI) a simple practical measure for routine clinical use. Clin Exp Dermatol 1994; 19: 210-6.

12. Szepietowski J, Salomon J, Finlay AY, et al. Dermatology Life Quality Index (DLQI): Polish version. Dermatol Klin 2004; 6: 63-70.

13. Lawson $V$, Lewis-Jones MS, Finlay AY, et al. The family impact of childhood atopic dermatitis: the Dermatitis Impact Questionnaire. Br J Dermatol 1998; 138: 107-13.

14. Magin P, Adams J, Heading G, et al. Psychological sequelae of acne vulgaris of a qualitative study. Can Fam Physician 2006; 52: 978-9.

15. Dooley G, Finlay AY. Personal construct system of psoriatic patients. Clin Exp Dermatol 1990; 15: 401-3.

16. Ginsburg IH, Link BG. Psychosocial consequences of rejection and stigma feelings in psoriasis patients. Int J Dermatol 1993; 32: 587-91.

17. Stankler $L$. The effect of psoriasis on the sufferer. Clin Exp Dermatol 1981; 6: 303-6.

18. Devrimci-Ozguven H, Kundakci N, Kumbasar H, Boyvat A. The depression, anxiety, life satisfaction and affective expression levels in psoriasis patients. J Eur Acad Dermatol Venereol 2000; 14: 267-71.

19. Gupta MA, Gupta AK. Depression and suicidal ideation in dermatology patients with acne, alopecia areata, atopic dermatitis and psoriasis. Br J Dermatol 1998; 139: 846-50.

20. Roenick RK, Roenick HH. Sex differences in the psychological effects of psoriasis. Cutis 1978; 21: 529-33.

21. Reich A, Welz-Kubia K, Rams $七$. Apprehension of the disease by patients suffering from psoriasis. Adv Dermatol Allergol 2014; 31: 289-93.

22. Janowski K. Problematyka jakości życia w chorobach dermatologicznych. In: Jakość życia w chorobie. Steuden S, Okła W (eds). Wyd. KUL, Lublin 2006; 49-55.
23. Łakuta P, Marcinkiewicz K, Bergler-Czop B, et al. Associations between site of skin lesions and depression, social anxiety, body-related emotions and feelings of stigmatization in psoriasis patient. Adv Dermatol Allergol 2018; 35: 60-6.

24. Kapała W. Jakość w szpitalnych oddziałach zabiegowych. Przewodnik Menedżera Zdrowia 2002; 9: 9-11.

25. Maciąg R. Badania satysfakcji pacjentów - wskazówki metodologiczne. Zdr Publ 2001; 111: 48-52.

26. Wyrzykowska M. Ocena opieki pielęgniarskiej w opinii pacjentów. Piel Chirurg Angiol 2007; 1: 3-10.

27. Miniszewska J, Chodkiewicz J, Zalewska A. Psychodermatologia - nowe wyzwanie dla psychologii. Now Psychol 2004; 3: 21-9. 